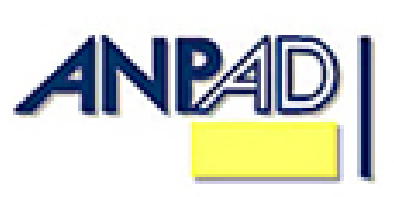

Disponível em

http://www.anpad.org.br/rac

RAC, Curitiba, v. 15 , n. 1 , art. 8 , pp. 138-157, Jan./Fev. 2011

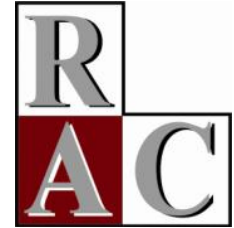

\title{
Teoria dos Jogos e Microssociologia: Avenidas de Colaboração
}

\section{Game Theory and Microsociology: Avenues of Collaboration}

Charles Kirschbaum * E-mail: charlesk1@insper.org.br Instituto de Ensino e Pesquisa São Paulo, SP, Brasil.

Tatiana Iwai

E-mail: tatiana.iwai@esag.edu.br Escola Superior de Administração e Gestão São Paulo, SP, Brasil.

* Endereço: Charles Kirschbaum

Rua Quatá, 300, São Paulo/SP, 04546-042.

Copyright (C) 2011 RAC. Todos os direitos, até mesmo de tradução, são reservados. É permitido citar parte de artigos sem autorização prévia, desde que seja identificada a fonte. 


\title{
Resumo
}

A abordagem da Teoria dos Jogos tem sido frutífera em analisar situações estratégicas, enquanto seus pressupostos têm atraído críticas importantes do campo sociológico. As críticas sociológicas à TJ apresentam limitações na explicação da confiança entre indivíduos. Da mesma forma, os dilemas sociais parecem obstruir a possibilidade de explicação da cooperação. No limite, as vertentes sociológicas são contrapostas à TJ. Esse artigo explora as possíveis avenidas de colaboração entre a TJ e a microssociologia. Recuperamos neste artigo as vertentes sociológicas que reconhecem o enraizamento social da escolha racional, principalmente na utilização da comunicação e linguagem. Argumentamos que a construção de experimentos econômicos que envolvam dilemas sociais, mas que são permeados por momentos de comunicação entre os atores, permite a geração de material passível de análise qualitativa sob a perspectiva de quadros interpretativos (Goffman) e convenções (Boltanski e Thevenot) e interação com atores não-humanos (Latour).

Palavras-chave: interação estratégica; cooperação; conflito; microssociologia; experimentos.

\begin{abstract}
The Game Theory approach has been fruitful in analyzing strategic contexts, while its assumptions have attracted important criticism from the sociological field. Specifically, the sociological criticism portrays GT as failing to explain trust among individuals. In addition, social dilemmas seem to obscure the explanation of how cooperation is possible. Taking this comparison to its extreme, one is led to believe that the sociological thinking sharply opposes GT. In contrast, this article explores the possible avenues of collaboration between GT and microsociology. We recover in this article the sociological approaches that recognize the social embeddedness of rational choice, mainly by the use of communication and language. We argue that the construction of economic experiments involving social dilemmas, and punctuated with dialogue, generate rich material for qualitative analysis. We propose that this qualitative material be interpreted under frame analysis (Goffman), conventions (Boltanski \& Thevenot) and non-human interactions (Latour).
\end{abstract}

Key words: strategic interaction; cooperation; conflict; microsociology; experiments. 


\section{Introdução}

A teoria dos jogos (TJ) oferece alguns caminhos para a investigação da interação estratégica: o instrumental de analisar contextos, onde os atores têm suas estratégias interdependentes. Essa abordagem procurou desenvolver alguns modelos para caracterizar esse tipo de interação. Por derivar da economia, essa linha teórica assumiu uma série de pressupostos para a construção de modelos sucintos. Tais pressupostos cobrem vasta gama de escolhas: como concebemos o agente da ação, as alternativas disponíveis aos atores antes da ação, os objetivos da teoria, qual o grau de intersubjetividade assumida, entre outras.

A TJ ganha uma atração especial, quando propõe problemas que nos ajudam a expressar situações reais de forma estilizada e simples. São de especial interesse os modelos de dilemas sociais, em que a TJ descreve situações cuja racionalidade instrumental individual é contrária ao bem coletivo. Esses modelos foram utilizados por uma série de autores na disciplina de Estratégia, Teoria das Organizações para descrever situações empresariais, desde problemas de cooperação em alianças estratégicas até guerra de preços.

Em sua versão ortodoxa, a TJ toma uma série de pressupostos que a torna ao mesmo tempo elegante pela sua simplicidade e problemática pela limitação de poder explicativo. Essa limitação tem aberto um flanco para várias críticas, especialmente oriundas de sociólogos. Entre as críticas mais comuns, encontramos a problematização da racionalidade instrumental como única lógica explicativa do comportamento individual, no pressuposto de intersubjetividade dos atores, e a precária endogeneização das estruturas e relações sociais nos modelos econômicos.

Desse ponto de vista, a Teoria dos Jogos, assim como a abordagem de Escolha Racional, é comumente representada como antípoda da abordagem sociológica: seus pressupostos ontológicos do indivíduo e epistemológicos do que pode ser conhecido e compartilhado pelos autores diferem radicalmente. Em termos substantivos, a sociologia critica a TJ por não conseguir explicar como é possível a cooperação. Consequentemente teríamos motivos abundantes para rechaçar qualquer articulação entre a TJ e abordagens sociológicas que diferissem da Escola de Escolha Racional.

Entretanto, advogamos que a Teoria dos Jogos, assim como as abordagens de Escolha Racional, podem ser consideradas como casos particulares e contrafactuais das interações sociais. A Escolha Racional teria seu escopo englobado pela investigação sociológica mais ampla. Munido dessa perspectiva, este artigo tem como objetivo: (a) rever os modelos básicos da Teoria dos Jogos; (b) apresentar as principais críticas sociológicas; (c) apresentar os argumentos que submetem a TJ à teoria sociológica; e (d) propor os experimentos como uma abordagem metodológica que pode conjugar as abordagens da TJ com aquelas da microssociologia.

\section{Teoria dos Jogos e os Dilemas Sociais: como a Cooperação é Possível?}

Um jogo pode ser definido pelos seguintes elementos: conjunto de jogadores, conjunto de alternativas ou estratégias de ação e, para cada estratégia, conjunto de ganhos recebidos por cada jogador (Kreps, 1990). A teoria dos jogos, cuja formulação inicial remonta ao trabalho de Neumann e Morgenstern (1944) sobre interação dos agentes racionais, em sua vertente mais determinista, busca a determinação do resultado dessa interação a priori da ação. 


\section{Dilemas Sociais}

Das diversas possibilidades de jogos, vale usarmos os dilemas sociais que, de acordo com Heckathorn (2001), tratam dos principais problemas apresentados pela escola de Escolha Racional. Assim, a partir dos dilemas, podemos discorrer tanto sobre as contribuições da teoria dos jogos, como sobre os principais pressupostos utilizados em seus modelos.

Dilemas sociais são situações em que a racionalidade individual leva a uma irracionalidade coletiva, à medida que o comportamento individual utilitário leva a situações em que todos estão piores. Desse modo, ao fazer aquilo que parece individualmente racional e razoável, indivíduos acabam com resultados piores do que aqueles que seriam encontrados, caso eles não tivessem feito essa escolha (Dawes \& Messick, 2000).

Nesse sentido, um dilema social é uma armadilha coletiva simétrica, em que a existência de estrutura de incentivos idêntica para todos os participantes os leva a responder a esses incentivos, ignorando as consequências sociais, de maneira que todos eles são levados a uma situação pior do que estariam, caso tivessem ignorado esses incentivos individuais (Messick \& Brewer, 1983).

Assim, de acordo com Dawes (1980), dilemas sociais se caracterizam por, pelo menos, duas propriedades: (a) comportamento oportunista gera payoffs individuais maiores do que o comportamento cooperativo. No entanto, (b) todos os indivíduos recebam payoffs menores, caso todos prefiram trapacear em vez de cooperar. Com isso, em dilemas sociais, o que se observa é que ainda que o grupo de pessoas envolvidas entenda completamente a situação e esteja consciente de como cada uma das ações contribui para o resultado não desejado, eles ainda assim são incapazes de fazer algo a respeito.

Das metáforas mais utilizadas na literatura de dilemas sociais, podemos apontar aquelas que envolvem uma díade, ou seja, um dilema de apenas duas pessoas, como o dilema do prisioneiro; e aquelas que são jogos de múltiplos atores como a tragédia dos comuns e a provisão de bem público.

No caso do dilema de duas pessoas, envolvendo o exemplo clássico do dilema do prisioneiro, a história original envolve dois jogadores suspeitos de um crime. A polícia tem apenas provas circunstanciais contra os dois; assim ela precisa da confissão deles para conseguir condená-los à máxima pena possível. Para que isso seja possível, os dois cúmplices são separados em celas diferentes, ou seja, mantidos sem comunicação para que a polícia possa interrogar cada um deles em separado. Dessa maneira, cada um, separadamente, precisa escolher entre duas opções possíveis: testemunhar contra o outro ou manter-se em silêncio, ou seja, cooperar ou agir de modo oportunista, sem saber o que o outro irá fazer.

Como as autoridades possuem evidências apenas para assegurar uma condenação leve, se nenhum dos prisioneiros confessar, ambos serão condenados a uma pena leve (dois anos de prisão, por exemplo): esse resultado é aquele onde os jogadores optam pela cooperação mútua (ambos se mantêm em silêncio). No entanto, se um prisioneiro decidir acusar o outro e este se mantiver calado, o primeiro, que agiu de forma oportunista (acusou o outro) sairá livre e o segundo, que cooperou ao se manter calado, pegará uma sentença pesada (dez anos de prisão, por exemplo); se ambos se acusarem, os dois prisioneiros receberão uma condenação moderada (cinco anos de prisão cada, por exemplo).

Dessa maneira, por ganância ou por medo de ser explorado, cada jogador terá o melhor resultado ao acusar o outro do que manter-se calado, independentemente do que o outro decida fazer. No entanto, se ambos decidirem acusar-se (comportamento oportunista mútuo) ao invés de calar-se (comportamento cooperativo mútuo), ambos terão um resultado pior (sentença moderada) do que se tivessem cooperado (sentença leve). Eis o dilema. Com isso, usando a linguagem da TJ, o ponto de equilíbrio situa-se em alternativa sub-ótima para ambos.

Em jogos, envolvendo mais de dois jogadores, podemos distinguir ainda dois conjuntos de modelos, que variam em termos de custos e benefícios experimentados por cada jogador. No primeiro 
conjunto, temos o que pode ser chamado de armadilhas sociais. São arranjos, em que o comportamento que visa à premiação individual de curto prazo implica punição de longo prazo, tanto para o indivíduo como para os outros (Messick \& Brewer, 1983). Assim, o indivíduo é motivado a auferir um benefício imediato, que irá causar um custo compartilhado por todos. Entretanto, se todos forem levados pela racionalidade individual do benefício particular, o resultado será um desastre coletivo. Esse tipo de dilema refere-se ao que chamamos de tragédia dos comuns.

Assim, neste modelo, popularizado pelo seminal artigo de Garret Hardin (1968) na Science, o autor pede que vislumbremos um pasto aberto a todos e observa a estrutura da situação pela perspectiva de um pastor racional. Cada pastor aufere um benefício direto por cada animal colocado no pasto, mas arca com os custos de deterioração do espaço decorrentes tanto dos seus animais como dos outros pastores. Dessa maneira, cada pastor é motivado a alocar mais e mais animais, uma vez que ele ganha diretamente com seus próprios animais, mas apenas compartilha os custos resultantes da pastagem coletiva.

Analisando a situação, temos então: se cada pastor cooperar, ou seja, respeitar o limite natural de pastagem e renovação do espaço, alocando um rebanho limitado no lugar, eles poderão usufruir o pasto - que é a sua fonte de sobrevivência - por um tempo indeterminado (cooperação mútua). Porém, se cada pastor agir de maneira oportunista, ou seja, colocar o maior número possível de animais no pasto (oportunismo mútuo), este estará em pouco tempo totalmente destruído, levando todos a uma situação de completo desastre. Assim, novamente, temos que a racionalidade individual (que visa ao benefício próprio) leva a uma irracionalidade coletiva (resultado para todos por destruição do pasto).

A discussão atual entre países para o desenvolvimento de uma política de uso sustentável de recursos naturais exemplifica o dilema da tragédia dos comuns. Ao optarem pela cooperação, os países que aceitarem implementar políticas de emissão controlada de poluentes, dentre outras ações, terão um possível impacto negativo na atividade econômica local (arcando com os custos do uso controlado do recurso natural). Porém, ao agir de forma oportunista, ou seja, ao recusar a aceitação de políticas de uso sustentável dos recursos, a atividade econômica local de cada país até continuará aquecida; porém a preservação do meio ambiente, que é de interesse de todos os envolvidos, continuará sob ameaça de colapso.

No segundo conjunto de modelo de jogo de mais de dois jogadores, temos as cercas sociais. Estes arranjos se caracterizam por um incentivo de não tomar determinada ação; mas, quando não tomada por ninguém, ou tomada apenas por poucas pessoas, resulta em um estado em que todos estão piores do que se tivessem tomado tal decisão (Messick \& Brewer, 1983). Ou seja, o sujeito sofre os custos de gerar um benefício que é compartilhado por todos. Assim, cada um tem um incentivo para evitar esse custo; porém, se todos optarem por tal ação, todos os jogadores estarão piores em comparação ao resultado em que eles tivessem conseguido escalar essa cerca. Nesse tipo, temos os jogos de provisão de um bem comum. Portanto, no jogo de provisão de bem público, o problema é que um bem público é recurso de que todos podem beneficiar-se, independentemente de terem ajudado a prover ou não. Dessa maneira, uma característica básica de um jogo de bem comum envolve a nãoexclusão (Davis \& Holt, 1993), que se refere à impossibilidade de prevenir o consumo daqueles que não contribuíram na provisão do bem.

Por essa característica, em jogos de bem comum, há uma tentação de usufruir do bem sem contribuir para sua criação ou manutenção (Kollock, 1998). Com isso, ainda que a provisão do bem do grupo seja do interesse de cada um, os membros do grupo terão um incentivo para não contribuir e se aproveitar da contribuição dos outros.

Porém, o impulso de free-riding, ou seja, de agir de maneira oportunista, pode levar a uma situação em que não há contribuições suficientes para a provisão do bem e, com isso, todos acabam sofrendo dessa situação sub-ótima. Além da motivação da ganância, outra razão para não cooperar é o medo de ser explorado pelos outros, desperdiçando seu esforço em um investimento que provavelmente não renderá frutos (no caso, não será provido). 
A cooperação das firmas em alianças estratégicas pode caracterizar o problema da provisão de bem público. Imaginemos que duas firmas formem uma aliança para desenvolvimento de nova tecnologia que, se bem-sucedida, beneficiará ambas as empresas. Apesar disso, cada firma tem um incentivo para restringir a contribuição de recursos valiosos (repasse de tecnologia, por exemplo) na aliança e se aproveitar da contribuição do outro. Com isso, no limite, se ambas as empresas adotarem este comportamento oportunista, são poucas as chances de o projeto ser bem-sucedido, criando as rendas relacionais do projeto que até mesmo foram a grande razão para justificar a aliança.

\section{A Aplicabilidade da Teoria dos Jogos na Realidade Empresarial}

Ao lidar com esses elementos, a teoria dos jogos é capaz de fornecer grandes contribuições para a análise econômica de diversas situações. Talvez a mais óbvia contribuição, que remonta aos primeiros desenvolvimentos da teoria dos jogos, diz respeito a sua capacidade de fornecer uma taxonomia para contextos econômicos (Kreps, 1990). Por exemplo, o dilema do prisioneiro apresenta uma situação que pode ser facilmente transportada para a realidade empresarial. Imaginemos que, ao invés de prisioneiros, temos empresas que interagem estrategicamente em uma indústria. Elas não podem comunicar-se e assim são levadas a reduzir preços para conquistar uma fatia maior do mercado. Ora, no limite, ambas reduzirão o preço até frustrar completamente suas perspectivas de lucro. $\mathrm{O}$ interessante desse resultado é que ele se assemelha ao resultado previsto pelo equilíbrio perfeito da teoria econômica clássica, onde os produtores em situação de equilíbrio não conseguem capturar nenhum lucro econômico.

Assim, apesar dessa situação ser mais complexa que o jogo do dilema do prisioneiro por não envolver, na realidade empresarial, exatamente uma decisão binária (reduzir/ não reduzir preço), ela pertence a uma classe estratégica de situação que remete ao modelo. Dessa maneira, podemos esperar que, apesar de não sermos capazes de capturar todos os matizes de contextos particulares nos jogos, ao aprofundar nosso entendimento teórico sobre a interação dos jogadores em um jogo como o dilema do prisioneiro, podemos levantar os aspectos estratégicos básicos de várias situações econômicas, facilitando a compreensão da dinâmica de competição entre firmas rivais.

Pode-se argumentar que os jogos simples de forma estratégica (como o caso do dilema do prisioneiro), ao simular movimentos simultâneos, são estáticos e não conseguem captar o aspecto dinâmico de várias situações de competição e, com isso, são muito simplificados. No entanto, temos ainda os jogos de forma extensiva ou dinâmica que, ao simular movimentos sequenciais, são capazes de capturar a característica dinâmica de interações competitivas e, com isso, fornecer grandes insights sobre sinalizações, ameaças e promessas críveis ou não, reputação e retenção de entrada. Todos são elementos bastante caros para os estudos do campo de estratégia.

\section{O Equilíbrio Nash e seus Limites}

Das diversas contribuições feitas que ajudaram a erigir os modelos utilizados pela teoria dos jogos, vale ressaltar a idéia de equilíbrio proposta por John Nash. O autor propôs uma solução em que concebia os jogadores agindo da seguinte maneira: quando um jogador não conseguir melhorar os seus ganhos ao mudar de alternativa, ele não terá incentivos para mudar unilateralmente sua escolha. Se ambos os jogadores se encontrarem nessa situação, estarão em equilíbrio.

Quais são as condições para que os jogadores cheguem ao equilíbrio de Nash? São apontadas as seguintes exigências: (a) cada jogador acredita que todos os outros jogadores são racionais; (b) o jogo descreve corretamente a utilidade que cada jogador obterá; (c) os jogadores não fracassam na execução de suas estratégias; (d) os jogadores são suficientemente inteligentes para deduzir a solução; (e) cada jogador é racional; (f) cada jogador é egoísta no sentido que tenta maximizar sua utilidade. 
Sobre essas exigências, os críticos vêm tecendo uma gama de críticas que problematizam o uso do equilíbrio de Nash para problemas reais. Em primeiro lugar, a exigência de racionalidade dos itens (a), (d) e (e) parecem ser irreais. Em interações estratégicas reais, nem sempre os atores são dotados da racionalidade presumida por Nash, seja na concepção das próprias alternativas estratégicas, seja na crença de que os outros são racionais, ou na possibilidade de que os estrategistas efetivamente são capazes de resolver os problemas sofisticados propostos pela Teoria dos Jogos. O problema torna-se dramático, quando o jogador descobre que joga bem demais. Se a sua linha de raciocínio pressupõe a racionalidade do oponente, mas esse último não é tão hábil ou experiente quanto o primeiro, é possível que o último perca do primeiro.

Além disso, é difícil aceitar que os atores saibam a utilidade percebida de seus oponentes $a$ priori da interação do jogo, assim como conhecem todas as alternativas disponíveis antes de agir (Allison \& Zelikow, 1999). Pelo contrário, os atores estratégicos são capazes de desenvolver aprendizado mútuo sobre as utilidades percebidas apenas por meio da interação estratégica. A crítica aqui se assemelha muito à crítica tecida por Mintzberg e seus co-autores às Escolas Prescritivas de Estratégia (Mintzberg, Ahlstrand, \& Lampel, 2000): como é possível conceber a melhor solução estratégica a priori de sua implementação? Da mesma forma, indagamos como é possível entender os competidores sem interagir com eles. Essa crítica pode ser identificada como o problema da internalização do pensamento estratégico, que prescindiria da ação e externalização para a sua determinação.

Outro problema se apresenta, quando temos situações com vários pontos de equilíbrio. Sen (1970) demonstrou que, em várias situações, havia vários pontos de equilíbrio; nesses casos, a teoria dos jogos é de pouca ajuda para saber qual deles é a solução. Assim, os jogadores ainda necessitariam de fatores exógenos ao jogo para serem capazes de orientar a sua ação. Esses fatores externos não seriam necessariamente um agente regulador ou supervisionador. Elementos salientes poderiam orientar nessa decisão. Um exemplo clássico é o da escolha do lado de uma rua onde trafegam os carros (Colman, 2003). Nesse tipo de jogo, é de interesse de todos que todos andem do mesmo lado (seja do lado esquerdo ou direito). Entretanto, quando analisamos do ponto de vista da Teoria dos Jogos, ambas as soluções aparecem como pontos de equilíbrio possíveis. E efetivamente, alguns países adotaram o lado esquerdo, enquanto outros países adotaram o lado direito. As convenções sociais resolvem o impasse. Mas devemos salientar que tais convenções sociais não são oriundas do jogo, mas se estabelecem como solução para resolver o problema de múltiplos pontos de equilíbrio. Outro problema se dá na ausência de pontos de equilíbrio, ou se usarmos o jargão da Teoria dos Jogos, um coração vazio. Elster (1983) sugere que elementos normativos podem orientar os jogadores na solução de jogos com múltiplos pontos de equilíbrio.

\section{Abordagens Alternativas à Solução de Nash}

Em seu famoso trabalho The Evolution of Cooperation (1984), Robert Axelrod aplicou uma abordagem evolucionária para o dilema do prisioneiro, onde várias estratégias eram testadas em um torneio de computador. Para tanto, convidou especialistas em teoria dos jogos para enviar programas de computador com estratégias específicas para lidar com o dilema. Assim, cada programa tinha uma estratégia distinta de jogar. As estratégias superiores conseguiam maior pontuação em cada rodada. Aquelas com maior pontuação eram agraciadas com uma descendência mais numerosa, enquanto aquelas com menor pontuação tinham menor número de filhos (corresponde à abordagem de algoritmos genéticos). Após várias rodadas, a população convergia para a estratégia tit-for-tat, que basicamente se tratava de uma estratégia de reciprocidade, visto que o programa começava com cooperação e então fazia o que o outro jogador fez no movimento anterior.

Como se sabe, as outras estratégias não conseguiram sobreviver, mostrando que o tit-for-tat era superior a todas as outras estratégias em jogos interativos de dilema do prisioneiro. Como interpretar esse fenômeno? O tit-for-tat foi a estratégia evolutiva mais estável (e, por isso, no torneio de Axelrod, 
cresceu e se tornou a espécie de estratégia dominante), porque ela é gentil (nunca é a primeira a trapacear), capaz de retaliar (trapaceará na rodada, caso a contraparte tenha trapaceado na rodada anterior) e capaz de perdoar (volta a cooperar na rodada, caso a contraparte tenha voltado a cooperar na rodada anterior). Assim, o procedimento tit-for-tat apresenta um equilíbrio entre a competição e cooperação.

Quais são as vantagens dessa abordagem sobre as abordagens tradicionais da Teoria dos Jogos? Em primeiro lugar, essa abordagem não pressupõe a racionalidade construída na solução de Nash. Mesmo com atores agindo de forma irracional, a seleção das estratégias mais eficazes é oriunda da dinâmica evolutiva (Axelrod aplicou a teoria na análise de cooperação em sistemas biológicos). Novamente, vale a pena ressaltar: em nenhum momento, Axelrod constrói em sua simulação agentes deliberativos.

Em segundo lugar, essa abordagem tem a vantagem de apontar um equilíbrio ótimo, sem a necessidade de um agente coordenador dos atores envolvidos. Se até então o dilema dos prisioneiros é tradicionalmente resolvido com a instituição de um agente com poder de coerção, que impede que os atores escolham pela alternativa individualmente racional (Binmore, 1994), aqui esse equilíbrio se dá com a ausência de uma instituição formal coercitiva.

Entretanto, essa abordagem traz também alguns limitantes. Em primeiro lugar, a estabilidade evolucionária do tit-for-tat já foi desafiada (Boyd \& Lorberbeaum, 1987). De acordo com Bendor e Swistak (1997), o tit-for-tat não é fortemente estável, porque, apesar de ser a melhor estratégia de resposta, ela não é imbatível, uma vez que permite a coexistência de outras estratégias neutras na população. Com isso, apesar de dominar uma estratégia neutra $\mathrm{x}$, sob a invasão de uma terceira estratégia y, o tit-for-tat pode ser menos adaptado a y do que a estratégia x já existente na população. Tal fato pode desestabilizar todo o processo evolucionário subsequente. No caso do tit-for-tat, em simulações feitas, de fato, ele não se manteve estável sob múltiplas perturbações.

Em segundo lugar, essa solução presume que os sinais são eficientemente comunicados, ou seja, o emissor produz o sinal, ele é recebido pelo receptor e devidamente descodificado. Quando um ataque ocorre, tanto emissor quanto receptor concordariam que se tratou de uma ofensa. Por outro lado, quando alguma das partes se esforça por cooperar com a outra, não existe nenhuma dúvida sobre a sinceridade desse esforço. Entretanto, interações reais não estão livres de problemas de interpretação, sendo frequentes os casos em que um ator toma erroneamente a atitude de outro como ofensa. $\mathrm{O}$ problema da interpretação toma dimensão insuportável, quando acrescentamos a essa situação a predisposição dos atores de punirem-se uns aos outros após qualquer ofensa: os atores estarão também predispostos a interpretar os sinais recíprocos como ofensas: "the problem with tit-for-tat is that any mistake 'echoes' back and forth. One side punishes the other for a defection, and this sets off a chain reaction" ${ }^{(1)}$ (Dixit \& Nalebuff, 1991, p. 108). Um problema análogo é o pressuposto da comensurabilidade - assume-se que os atores conhecem a utilidade uns dos outros e que a forma dos indivíduos em avaliar as situações podem ser traduzidas em uma moeda única (Favereau, 2005).

Em resumo, existem evidências fortes de que, embora a teoria dos jogos consiga explicar o estabelecimento de dilemas sociais, há poucos subsídios para explicar a cooperação. Soluções como a de Nash (extritamente ligada à Escolha Racional) ou de Axelrod (utilizando-se de algoritmos genéticos) não permitem uma explicação sólida de como a cooperação é possível. A seguir, exploraremos as críticas e contribuições da sociologia à Escola de Escolha Racional, e a possibilidade de colaboração entre as abordagens. 


\section{Interlocutores na Sociologia: da Crítica à Colaboração}

\section{Crítica e incorporação da escola de escolha racional na sociologia}

Max Weber é lido por muitos sociólogos e economistas como um dos principais defensores do individualismo metodológico, abordagem teórica que, assim como a Escolha Racional na Economia, busca localizar na ação individual o principal fator explicativo dos fenômenos sociais (Coleman, 1990; Hedstrom \& Swedberg, 1996). No clássico "Economia e Sociedade", Weber (2009) propõe que a ação se torna social quando os indivíduos levam em consideração a ação dos outros. Dessa forma, o conceito weberiano de ação social é comparado e vinculado à idéia de equilíbrio Nash, em que atores racionais são levados a tomar decisões que maximizem sua utilidade; mas essa estratégia leva em consideração a ação de outros atores.

Abell (2000) recupera essa formulação e mostra que a apropriação da Escolha Racional do conceito weberiano de ação social é apenas uma das interpretações possíveis. Essa abordagem falha em incorporar o elemento interpretativista e fenomenológico, que levaria à concepção de ação localizada em contextos bem mais complexos e detalhados do que aqueles construídos nos jogos estilizados da Escolha Racional.

Em contrapartida, um número grande de sociólogos (influenciados diretamente por Weber) buscou mostrar como a ação social não levava apenas à maximização de utilidade, mas também à adequação a valores. Para Weber, ação não é sempre vinculada à maximização de utilidade; mas também tem elementos valorativos que podem apresentar-se como irracionais do ponto de vista da maximização de utilidade (Weber, 1978 citado em Swedberg, 2000). Em contraste com os estudantes de Escolha Racional, a explicação da origem desses valores não pode ser simplesmente resultado da interação estratégica (Abell, 2000). Pelo contrário, muitos desses valores têm origem exógena, institucional e histórica.

Anne Rawls (1992) recupera conceitos centrais da sociologia de Durkheim, ao propor que toda ação individual só é possível em um contexto social por duas razões centrais. Em primeiro lugar, a linguagem utilizada pelos indivíduos na comunicação em interações estratégicas é oriunda da estrutura social onde se encontram. Como seria possível, pergunta-se Rawls, qualquer comunicação que envolvesse indivíduos que transcendem o seu contexto social? Por outro lado, a própria concepção de indivíduo só é possível em relação ao contexto social. Se a cultura ou contexto social não permite um processo de individuação, não poderíamos ter o tipo de raciocínio autointeressado pressuposto pela Escolha Racional. O processo de individuação é fato social que mesmo Durkheim aponta em diversos pontos de sua obra.

As colocações de Rawls à primeira análise coloca a sociologia clássica em oposição à Teoria da Escolha Racional, seja em suas considerações ontológicas ou epistemológicas. A concepção ontológica do indivíduo é distinta, pois Rawls enxerga a agência indivídual como oriunda do processo social. Epistemologicamente também há distinção. Rawls enxerga a cognição e ação indivídual como coextensivas da estrutura social. As categorias cognitivas utilizadas pelos indivíduos, centrais na sua avaliação da interação estratégica, não são dadas a priori de sua sociabilização, mas dependem da sociabilização. É sabido, por exemplo, que choques culturais entre executivos podem levar ao final abrupto de processos de negociação. Assim, a idéia de maximização de utilidade defendida pela economia não pode ser pensada de forma desencarnada do contexto social (ver também Vaughan, 1998).

Entretanto, Rawls (1992) admite que exista interação estratégica, ainda que essa deva ser entendida sempre levando-se em conta o contexto social. A partir dessa intuição, podemos perguntarnos como é possível a ação estratégica, quando levamos em consideração o contexto social. Por um lado, a ideia de atores estrategicamente orientados, visando à maximização de sua utilidade, parece não corresponder à realidade social. Por outro lado, a explicação sociológica, que parte de uma 
dimensão macro da sociedade, arrisca eliminar a ação estratégica do leque de fenômenos sociais relevantes.

Em contraste, autores como Swedberg (2001) e Habermas (2003) reforçam o argumento contextualista de Rawls, ao situar a escola de Escolha Racional nos estudos sociológicos, evitando uma posição dicotômica. Swedberg argumenta que os estudos de escolha racional têm proposto situações contrafactuais que são úteis para testar a estabilidade de arranjos e relações sociais. Habermas situa a escola de escolha racional sob a égide subjetivista, por produzir modelos de ação vinculados aos interesses dos atores sociais: em contraposição aos modelos nomológicos, que não levam em consideração a ação individual. Entretanto, argumenta Habermas, essa abordagem não logra explicar como a intersubjetividade é construída. De forma conexa, Favereau (2005), um dos principais proponentes da escola convencionalista, evidencia como a análise da Escolha Racional não é capaz de explicar a origem das normas e valores, apenas a partir das interações estratégicas. Favereau, assim como Anne Rawls, propõe que a possibilidade de cooperação deve ser produzida por meio da linguagem, no momento em que os atores evocam ontologias coletivas que ganham realidade ao serem expressas pelos atores. Em outras palavras, a linguagem permite a evocação e criação de entidades coletivas, que não existiriam se a interação não utilizasse linguagem (em diretto contraste com o modelo de Axelrod). Assim como Habermas, Favereau propõe que a teoria social deve engajar-se numa crítica da linguagem empregada pelos atores sociais nas suas interações.

\section{Enquadrando a Interação Estratégica na Microssociologia}

\section{Cooperação e conflito nas interações}

Retomamos Simmel, para abordar os conflitos com potencial associativos. Por meio dos conflitos, as partes envolvidas são levadas a tomar conhecimento uma da outra; e assim estabelecem um reconhecimento mútuo inexistente anteriormente. Esse reconhecimento leva a um aprendizado, que pode ter um efeito contrário ao potencial disruptivo, tradicionalmente associado aos conflitos (Segre, 1998). O conflito pode ser importante para a manutenção da coesão social, ao possibilitar a troca de informação (Coser, 1956). Segundo Coser, relações que não dão vazão aos conflitos têm maior probabilidade de ruptura, quando os conflitos já não podem ser abafados.

De forma similar à Escolha Racional, Simmel pressupõe que os atores sociais têm conhecimento mútuo para permitir a interação. Entretanto, em contraste com a teoria da Escolha Racional, essa informação nunca é completa. Dessa forma, Simmel propõe que a interação geralmente ocorre entre dois polos: o da ignorância completa e o do conhecimento completo. Se há ignorância completa sobre a outra parte, a ação é inviável (Simmel, 1955). Por outro lado, se há informação completa, a ação torna-se trivial, como em cálculo de um sistema de equações. Essa ideia também é cara à Escola Convencionalista e seus seguidores (Favereau, 1997). Por exemplo, Stark (2009) sugere que é apenas devido à incerteza associada à geração de novos ativos que os atores em uma interação se engajam em aprendizado mútuo e abrem possibilidades de inovação.

Möllering (2001) estende a intuição simmeliana para investigar a criação e sustentação de confiança nas interações. De forma similar a Simmel, Möllering propõe que é necessária informação mútua para que seja possível a ação. No entanto essa informação é, na melhor das hipóteses, incompleta antes da interação. E mesmo que tenhamos acesso ao histórico comportamental do atores, nada garante que o comportamento futuro será consistente com o comportamento passado. Talvez justamente ao contrário: no momento em que o ator social tem consciência de que seu comportamento passado criou uma reputação que permite a sustentação de expectativas positivas, então ele tem um incentivo aumentado para agir oportunisticamente. Ou seja, a inferência gerada pela Escolha Racional a partir do comportamento histórico não é sustentada pela abordagem de Möllering. Dessa forma, se a ação não se sustenta apenas sobre o comportamento histórico dos atores, ela se sustenta sobre uma percepção subjetiva de que o ator que interage seguirá em um curso positivo. Esse elemento subjetivo 
aproxima-se mais de um salto de fé, pois há uma relativa suspensão do juízo, quando se sustenta a confiança em uma relação.

\section{A dimensão dramática das interações estratégicas}

Nessa seção, aproximaremos o pensamento de Goffman ao de Simmel, introduzindo a dimensão dramática do primeiro no entendimento das interações.

O texto clássico de Goffman (1959), oriundo de sua tese de doutorado, The Presentation of Self in Everyday Life marca sua contribuição para a construção da microssociologia nos Estados Unidos. Nessa obra, Goffman insiste em que a unidade central de análise na sociologia deve ser a interação social. Sob forte influência de Mead, Goffman propõe que é por meio de interações face a face que os indivíduos criam, recriam e sustentam suas identidades. A identidade social é estabelecida pela percepção do outro e da percepção de como o outro nos percebe.

Goffman postula que os atores buscarão sustentar a interação. A ordem interativa deve ser mantida, para que os atores possam respeitar-se mutuamente e manter os padrões recíprocos de deferência. Isso não significa, no entanto, que as interações são sempre livres de dificuldades. Pelo contrário, Goffman (1967) mostra que nem sempre os atores sociais são capazes de controle emocional suficiente para manter a interação. Quando isso ocorre há perda da face: fica evidente para os envolvidos que o ator não é capaz de sustentar o desemprenho. Nessas situações, sugere Goffman, os atores envolvidos em uma interação se esforçarão para salvar a face daquele que não pode sustentar o seu desempenho. Esse esforço surge como tentativa de restabelecer a ordem interativa.

Goffman (1959) é vastamente citado como referência central do fenômeno de gestão da imagem. Se a vida social se dá por meio das interações e é razoável assumir a boa fé dos atores sociais em manter a ordem interativa ao crer na veracidade das aparências, é possível que haja ação oportunística na manipulação das aparências. Goffman elabora os conceitos de front-stage e backstage para propor regiões da vida social onde o ator está mais (ou menos) visível e exposto ao controle. Entre essas duas regiões, sugere Goffman, os atores sociais desenvolvem suas ações, sempre alertas para que não sejam flagrados e consequentemente punidos.

\section{Quadros de referência}

Para Goffman (1969a), a intersubjetividade não é dada, mas construída pela interação. Essa abordagem contrasta com o posicionamento tradicional de pesquisadores em Escolha Racional, que tomam o conhecimento mútuo (de preferências e escolhas disponíveis) a priori da interação.

Goffman sugere que as informações trocadas pelos indivíduos são interpretadas por meio de quadros de referência compartilhados e o estabelecimento desses quadros pode ser fruto de negociação. No curso da interação, os atores sinalizam uns aos outros uma possível mudança de quadro de referência, quando, por exemplo, há transição entre uma conversa mais informal e descomprometida para uma conversa sobre negócios. Essas sinalizações lubrificam as transições entre contextos sociais diferentes, ainda que envolvam os mesmos atores (Goffman, 1974). A mesma preocupação com os efeitos de enquadramento podem ser observados na teoria Convencionalista (Favereau, 2005; Thevenot, 2002).

Thevenot (2002) recupera a ideia de enquadramento de Goffman para vincular os possíveis enquadramentos a distintas convenções, como, por exemplo, o mundo da indústria, ou o mundo do comércio. Quando atores orientados por convenções distintas interagem, é provável que tentem negociar qual será o enquadramento vigente na interação. Desse ponto de vista, Thevenot sugere que existe na interação uma negociação de segunda-ordem: o terreno que irá reger o transcorrer da interação. Uma alternativa à preponderância de uma convenção sobre a outra é o estabelecimento de meio-termos (compromises), que podem vir a ser tácitos e facilitar a comensurabilidade de entidades 
que são incomensuráveis, por serem enquadrados de formas distintas em diferentes mundos (Boltanski \& Thevenot, 1991).

Em contraste, a dinâmica estratégica nessa negociação pode vir a problematizar a viabilidade da interação. Ao elaborar a teoria de quadros de referência, Goffman parte de situações colaborativas corriqueiras, sem incluir o elemento estratégico competitivo. Ao transplantar a ideia de quadros de referência para o contexto estratégico, Goffman retorna a sua ideia original de gestão de imagem, concluindo assim: se os atores sociais são motivados a manipular os sinais para manter uma face, então, em outro nível, poderão manipular os sinais para manipular os quadros de referência do interlocutor ou do observador. A dimensão estratégica do uso da linguagem é evidenciada por Goffman (1969a). Como então é possível a manutenção da interação social, quando, em tantos níveis, a manipulação estratégica arrisca levar os atores a romper com a cooperação? Goffman apoia-se em Schelling e sua obra Strategy of Conflict (1980), ao insistir no uso apropriado da linguagem como elemento importante, mas não suficiente, para a manutenção da confiança (Goffman, 1969a). Para tornar esse ponto mais concreto, gostaríamos de evocar os experimentos de laboratório de negociação. Em experimentos onde há várias rodadas, os indivíduos envolvidos têm a oportunidade de interagir e reestabelecer, por meio de interação face a face o diálogo e a confiança. Vários autores apontam que a habilidade dos indivíduos em convencer os seus observadores, que irá comportar-se de forma colaborativa, é crucial na probabilidade de reestabelecer uma predisposição positiva. Em contraste, aqueles indivíduos que não têm essa habilidade discursiva, que inclui a mobilização de justificativas convincentes, acaba tendo maior fracasso no restabelecimento da confiança (Bottom, Gibson, Daniels, \& Murnigham, 2002). Mas novamente Goffman vai além: se é possível enganar por meio de um comportamento traiçoeiro, é possível também enganar com promessas sedutoras de reconciliação. No limite, parece não haver possibilidade de estabelecimento de comportamento colaborativo. Ainda assim, Goffman (1969a) apela para o elemento que julga irredutível de sua microssociologia: a interação face a face, como algo dificilmente manipulável:

It can be assumed that between any two parties in face-to-face interaction, standards of mutual respect - albeit sometimes quite minimal - will obtain. ... In short, face-to-face interaction is an arena of conduct, not merely expression and communication, and conduct is judged first off not in regard to sincerity and candor, but 'suitability'. (2) (p. 168)

Em resumo, o que Goffman (1969b) defende no decorrer de sua obra, e culmina com Strategic Interaction é que não é possível haver coordenação entre as partes sem que haja a interação face a face. Essa interação ajuda-nos a entender como a linguagem compartilhada é preservada e defendida contra o risco de degeneração na interação estratégica. De forma correlata, é apenas na interação social que os atores obtêm informações sobre os interesses mútuos e conhecimentos compartilhados. É durante as várias interações que se constrói e reconstrói o campo intersubjetivo que dá o contexto necessário às escolhas estratégicas (Goffman, 1969b). As decisões estratégicas não podem ser, no limite, tomadas em sua totalidade a priori da ação, e prescindindo da comunicação.

A abordagem de Goffman (1969b) sugere que a teoria dos jogos pode beneficiar-se de metodologias que forneçam ferramental para analisar as trocas de informações durante as interações, e os quadros cognitivos e formação de intersubjetividade durante a comunicação entre as partes.

\section{A Inclusão dos Objetos para a Localização e Globalização das Interações}

Tomamos a abordagem goffmaniana para entender como os atores constroem e sustentam a ação social. Se, por um lado, essa abordagem trouxe à sociologia a possibilidade de construção de uma microssociologia, por outro lado, ela levou seus herdeiros diretos à indiferença em relação aos efeitos macroestruturais sobre as interações (Coulon, 1995; Latour, 1996, radicaliza esse posicionamento, aproximando o interacionismo da Escolha Racional). Além disso, muitas tentativas de justaposição da dimensão macroestrutural à dimensão interacional termina por forçar a existência de construções 
ontológicas sustentáveis apenas ex-post à pesquisa empírica (Latour, 1996, cita entre outros, o contrato social rousseauniano ou os estudos estatísticos da escola parsoniana).

Latour (1996) toma uma estratégia distinta para essa discussão. Ao invés de aceitar a estrutura social como algo dado e vigente no momento das interações, Latour compartilha com os etnometodólogos e os interacionistas simbólicos a idéia de que a interação social é o nível privilegiado da análise da ação social. Entretanto, Latour não acredita que a interação face a face, por si só, seja capaz de manter a estrutura social da forma como a experimentamos no dia a dia. Para tanto, Latour compara as interações humanas com as interações dos primatas, para evidenciar como em (quase) cada nova interação os primatas são forçados a restabelecer o relacionamento e como cada interação está sempre sujeita à interferência de outros indivíduos no bando. Em contraste, nós, humanos, carregaríamos de uma interação a outra a memória, que nos dá a impressão de uma estrutura social perene. Por outro lado, nós, humanos, seríamos capazes de nos engajar em interações, sem que esses encontros fossem sempre expostos ao olhar de todos na comunidade; dessa forma, somos também capazes de proteger as nossas interações. Tudo aquilo que não é imediatamente posto como interferência seria mediado pela memória. Latour nomeia o movimento de inserir, em uma interação, elementos de globalização alheios a ela, ao passo que o movimento de proteção da interação do mundo exterior é chamado de localização.

A memória que Latour evoca como elemento vinculado à estrutura social não é sustentada apenas pela capacidade cognitiva dos atores humanos, envolvidos diretamente na interação face a face. Latour sugere que, sem a ajuda dos objetos e da dimensão material da ação humana, não haveria como sustentar a estrutura social, ou, dito de outra forma, a estrutura social nada mais é que aquilo que se torna durável com o auxílio da tecnologia (Latour, 1991). Se os objetos emergem como elementos actantes nas interações, devemos, sugere Latour, incorporá-los na análise, mesmo no contexto de interações supostamente isoladas e protegidas, como nos experimentos sugeridos na Economia Experimental e analisados na próxima seção (Latour, 1996).

No contexto de construção e sustentação da confiança nas relações intra e inter-organizacionais, os objetos fronteiriços (boundary objects) possibilitam algum grau de continuidade entre as interações (Sapsed \& Salter, 2004). Como vimos acima, objetos fronteiriços podem auxiliar na consolidação de arranjos locais, quando os atores são orientados por convenções distintas (Thevenot, 2002).

Por outro lado, embora a ação social seja (parcialmente) sustentada pela existência e persistência de objetos, isso não significa que esses objetos terão o efeito e funcionamento previsíto e sob o controle completo dos agentes humanos (Tureta \& Alcadipani, 2009). A problematização da estabilidade e continuidade dos objetos torna o trabalho de campo mais exigente, mas traz como vantagem a possibilidade de prescindirmos de reificação da estrutura social para explicar as interações observadas. Na próxima seção, mostramos como as contribuições da microssociologia podem ser integradas ao desenho de experimentos em laboratórios.

\section{A Metodologia de Experimentos}

Apesar das diversas críticas, diversos estudos continuam sendo desenvolvidos, com inspiração na teoria dos jogos; mas sem limitar-se a ela (Sauaia \& Zerrenner, 2009). Esses estudos vêm até mesmo aprofundando, cada vez mais, o entendimento da tensão intrínseca entre cooperação e competição, em situações de interdependência de ação e, neste processo, tentam acatar e absorver as críticas aos pressupostos duros da teoria dos jogos, refinando o modelo como um todo.

Assim, além de usar variáveis mediadoras estruturais para atenuar o oportunismo e garantir cooperação - número de iterações (Davis \& Holt, 1993; Ledyard, 1995; Parkhe, 1993), estrutura de payoffs (Davis \& Holt, 1993; Kollock, 1998; Komorita, Sweeney, \& Kravitz, 1980; Ledyard, 1995), tamanho do grupo (Dawes, 1980; Kollock, 1998; Marwell \& Ames, 1980; Messick \& Brewer, 1983; 
Olson, 1965), especificidade de ativo (Antiqueira, Saes, \& Lazzarini, 2007) pontos de provisão (Ledyard, 1995; Marwell \& Ames, 1980) e sanções formais (Ostrom, Walker, \& Gardner, 1992; Tenbrunsel \& Messick, 1999) - outros mediadores motivacionais (Kollock, 1998), que trabalham com pressupostos mais flexíveis sobre racionalidade e utilitarismo, vêm ganhando força.

Dessa maneira, preferências sociais (Fehr \& Fischbacher, 2002; Gillespie, Brett, \& Weingart, 2000; Liebrand, Wilke, Vogel, \& Wolters, 1986; McClintock \& Liebrand, 1988; Offerman, Sonnemans, \& Schram, 1996) e comunicação (Bottom et al., 2002; Davis \& Holt, 1993; Dawes, 1980; Kollock, 1998; Ledyard, 1995; Ostrom et al., 1992; Shapiro, 1991), por exemplo, passam a compor também o universo das situações analisadas pela teoria dos jogos.

A inserção da heterogeneidade das preferências sociais desafia a hipótese da motivação exclusivamente pelo interesse próprio material, que domina o pensamento econômico. Nessa linha, se há pessoas motivadas pelo interesse próprio, também há pessoas que se importam não apenas com seus resultados, mas também com a distribuição de resultados para outros agentes relevantes (Fehr \& Fischbacher, 2002; em consonância com a escola convencionalista - Favereau, 2005), seja por motivos de reciprocidade ou aversão a inequidades.

Imaginemos, por exemplo, uma situação em que dois sujeitos precisam entrar em acordo sobre a divisão de uma dada quantia de dinheiro. O sujeito A faz a proposta de como será a divisão e a pessoa $B$ pode aceitar ou rejeitar a divisão proposta. No caso de não-acordo, os dois não recebem nada; caso haja acordo, a proposta de A é implementada. A predição econômica dura argumenta que, uma vez que os dois são racionais e egoístas, o equilíbrio ocorrerá com um resultado extremo: a pessoa B aceitará qualquer valor positivo (melhor do que não receber nada) e a pessoa A fará uma proposta de divisão que aloque o mínimo possível do dinheiro para B. De acordo com Fehr e Fischbacher (2002), diversos experimentos mostraram que propostas que alocavam menos que $20 \%$ do dinheiro para $\mathrm{B}$ eram, em média, rejeitadas em 40 a $60 \%$ dos casos. As justificativas dadas pelos sujeitos tipo B para os não-acordos foram que viam as propostas como injustas.

Em uma linha muito próxima, diversos outros experimentos vêm sendo desenhados e executados com o uso de variáveis que buscam justamente revisar a hipótese utilitarista de comportamento e que mostram como reciprocidade, percepção de justiça e motivação intrínseca impactam a decisão do jogador e, portanto, precisam ser incorporadas ao modelo.

Mais do que simplesmente adicionar variáveis que tragam elementos estruturais à interação pelas portas do fundo, como em um pastiche teórico (Favereau, 2005), é necessário colocar a comunicação como central na análise dos experimentos, uma vez que é na atividade discursiva que se cristalizam entidades coletivas que apoiam os significados compartilhados. Em paralelo a essa consideração, outro mecanismo vem sendo utilizado constantemente para enquadrar a questão do contexto social e suas variáveis correlatas nos jogos: a comunicação. Modelos formais de comportamento econômico racional argumentam que talk is cheap (Malhorta \& Murnighan, 2002). Em outras palavras, sugere-se que nenhuma das partes se beneficia ao comunicar suas verdadeiras intenções à contraparte e agir de maneira confiável, uma vez que o potencial oportunista das partes não pode ser verificado ex-ante (Pillutla \& Murnighan, 1995). Com isso, a menos que haja um mecanismo de incentivos compatível, criado exogenamente, estipulando penalidades por comportamento não-cooperativo, as partes não agem de maneira cooperativa.

Entretanto diversos experimentos, que usam o mecanismo de comunicação, apontam de maneira consistente como as palavras têm poder significativo na facilitação da cooperação mútua (Bottom, et al., 2002; Davis \& Holt, 1993; Dawes, 1980; Kollock, 1998; Ledyard, 1995; Ostrom et al., 1992; Shapiro, 1991). Dentre as razões mais apontadas para o aumento na cooperação, podemos distinguir quatro principais justificativas (Messick \& Brewer, 1983). Primeiro, a comunicação permite que os membros do grupo colham informações sobre as escolhas que os outros tendem a fazer, introduzindo algumas normas de grupo e pressões conformativas em favor de escolhas cooperativas. Segundo, ao possibilitar a promessa por determinada escolha - considerando que as pessoas tendem geralmente a julgar as palavras dos outros (mesmo pessoas estranhas) como confiáveis, ainda que não haja 
evidência clara para apoiar tal percepção (Malhorta \& Murnighan, 2002), cria-se um senso de confiança entre as partes (desde que as promessas não sejam quebradas consistentemente), diminuindo-se o risco percebido em tomar a decisão cooperativa sozinho e, com isso, ser o explorado. Terceiro, a discussão oferece a oportunidade do uso de dissuasão moral entre os membros do grupo, enfatizando o que é certo e apropriado de fazer. Por último, a discussão de um determinado problema pode criar um senso de identidade de grupo, que faz com que a distância psicológica entre o interesse privado e o coletivo diminua, aumentando a probabilidade de decisões que visam ao interesse coletivo; fomenta-se, dessa forma, o nível de cooperação entre o grupo. Dessa maneira, os atores não respondem unicamente baseados em seus interesses individuais, mas são constrangidos pelas posições que ocupam na estruturas sociais da qual fazem parte (Marsden, 1981).

Por exemplo, Ostrom (2000) cita um interessante experimento de Frohlich e Oppenheimer (1996). Os autores simularam um jogo de dilema do prisioneiro. Um conjunto de grupos jogou o dilema na sua forma regular, com alguns grupos usando o mecanismo da comunicação e outros não. Em um segundo conjunto de grupos, utilizou-se um mecanismo de incentivo externamente imposto aos jogadores e que foi desenhado para aumentar as escolhas cooperativas. De fato, na primeira fase do jogo, o segundo conjunto de grupo atingiu melhores níveis de cooperação. No entanto, em uma segunda fase do jogo, quando o segundo conjunto de grupos passou a jogar o dilema na sua forma regular (sem o mecanismo de incentivos), os níveis de cooperação destes grupos caíram consideravelmente e ficaram em um patamar bem inferior aos dos grupos de controle (primeiro conjunto de grupos que sempre jogou o dilema na sua forma regular), especialmente aqueles que puderam comunicar-se. Tais resultados nos mostram não apenas que um mecanismo de incentivos exógeno tem efeito transitório, mas que as normas de grupo, promovidas pela comunicação, impactam consideravelmente a ação do jogador. Assim, a comunicação, ao permitir a emersão e desenvolvimento de normas sociais e códigos de conduta implícitos e o desenvolvimento de um histórico de relacionamento entre as partes no jogo, pretende simular situações em que o contexto tem impacto na ação social.

Embora a comunicação tenha sido identificada como importante mecanismo de regeneração das relações sociais em contextos estratégicos, a maioria dos estudos não toma a comunicação em si como material de análise. Estudos, como de Bottom et al. (2002), contemplam tipos de justificativas empregadas na comunicação (em relação ao contexto das interações) para o reestabelecimento da confiança na relação são exceções. Propomos que os experimentos de laboratório promovam situações em que os indivíduos envolvidos sejam levados a empregar repertórios culturais e quadros interpretativos que levem ao reenquadramento da interação estratégica. A análise dessas interações, segundo a abordagem da microssociologia pode ser uma contribuição importante para o entendimento das interações estratégicas, mas também sobre o repertório cultural, colocado em ação em situações específicas (Swidler, 1986).

\section{Conclusões}

Gostaríamos de sintetizar as críticas à Escola de Escolha Racional. Sua tradição enfrenta as seguintes críticas: (a) pressupõe uma racionalidade ampla e a priori dos envolvidos; (b) assume a construção de intersubjetividade dada; (c) corre o risco de gerar dilemas insolúveis (muitos pontos de equilíbrio ou nenhum ponto de equilíbrio); (d) leva o estrategista a retirar a ênfase na ação em favor da análise; (e) frequentemente gera resultados que não correspondem aos dados empíricos experimentais. Os desenvolvimentos e correções de rumo propostos por Camerer (1991) podem não ser suficientes: (f) equilíbrios evolutivos se dão em periodo de tempo maior que o disponível para a tomada de decisão; (g) as normas e convenções que ajudam a evitar alguns dilemas são assumidas como exógenas à interação; (h) é difícil explicar como a confiança é sustentada. Confiança parece ser sempre epifenomenal na modelagem da Escolha Racional, enquanto variável resultante da interação estratégica. 
Mostramos neste artigo que a sociologia, e particularmente a microssociologia, tem fornecido explicações alternativas e gerado fatos empíricos complementares às intuições oriundas da Escolha Racional. Podemos sintetizar essas contribuições em três pontos. Em primeiro lugar, a ação não pode ser entendida fora do contexto social em que se encontra. Em segundo lugar, a linguagem é o meio privilegiado de sinalização entre os atores e é altamente contingente à interpretação dos atores envolvidos. Essa linguagem não é produzida na interação estratégica, mas é utilizada pelos atores durante a interação. A intersubjetividade é construída ao longo da interação e não é dada a priori. Elementos como objetos podem ser incluídos na análise, com o fim de auxiliar a explicação da construção e sustentação dos significados compartilhados.

Ao problematizar a intersubjetividade, a microssociologia é levada a endogeneizá-la em sua análise: o reconhecimento mútuo é constitutivo do jogo e ao mesmo tempo é contruído pelo jogo em andamento. Seria erro assumir que, para a microssociologia, a confiança é assegurada. O risco de ruptura e traição nos moldes da intuição de dilemas sociais da Escolha Racional persiste; mas agora o material de análise não é reduzido à escolha estratégica, porém se espraia por todo o processo de construção de sentido compartilhado entre os atores.

Como resposta a muitas dessas críticas, os modelos de inspiração na teoria dos jogos se vêm refinando e tentam inserir variáveis de contexto social na análise das interações estratégicas dos atores. Conforme comentado anteriormente, diversos são os estudos de base experimental que usam a comunicação como meio para analisar o impacto de elementos como conformação a normas sociais, confiança, reciprocidade e identidade de grupo na decisão de cooperação. No entanto o problema é que se privilegia o foco nos resultados da comunicação e não necessariamente em seu conteúdo.

Nesse sentido, se o impacto da comunicação (e dos elementos informais que ela carrega consigo) na decisão do ator já estão devidamente comprovados, pouco se sabe sobre a dinâmica social que se desenvolve no processo, para resultar nos efeitos positivos sobre níveis de cooperação encontrados.

Nessa linha, abre-se grande espaço para maior diálogo entre os modelos sociológicos de análise de interações sociais e os modelos de inspiração na teoria dos jogos. Por exemplo, alguns estudos (Pillutla \& Chen, 1999) vêm mostrando que diferentes descrições e conteúdos contextuais (com problemas de decisão idênticos atachados) levam a resultados diferentes de atitudes em face do risco e competição entre atores. Nessa linha de investigação, o contexto deixa de ser variável decorativa e passa a ser fator central na lógica de raciocínio e julgamento humano. A microssociologia problematiza também a forma como os atores leem e negociam o contexto, como vimos com as noções de enquadramento de Goffman, e os movimentos de localização e globalização propostos por Latour.

A forma como os atores concebem o seu contexto leva a possíveis papéis a serem desempenhado; portanto levam a um particular conjunto de normas de conduta. Assim, bem além da simples inclusão de preferências sociais trazidas por cada ator, mais rico e interessante pode ser pensar que os atores enfrentam uma nova situação (em nosso caso, o dilema revestido de uma determinada contextualização), primeiramente acessando seu repositório pessoal de experiências passadas em situações similares; com isso reavivam as normas implícitas aplicáveis àquela situação, fornecendo um esquema ou script, que pode ser a base cognitiva da ação. No entanto a análise pode tornar-se ainda mais interessante, se lhe agregarmos os quadros de referência desenvolvidos por Goffman (1974). O script não é estático. À medida que as pessoas interagem, elas passam a negociar significados das suas ações por meio da observação dos comportamentos e de outras sinalizações dos outros atores; com isso vão alterando os próprios scripts pessoais, formando uma dinâmica toda particular de manipulação, convencimento, percepção e ação.

Finalmente, poderíamos argumentar que os experimentos não são adequados metodologicamente, dado que criam situações artificiais não generalizáveis para ambientes naturais. Em contraste, mostramos o contrário: são os experimentos que são infiltrados pela realidade lá fora, seja mediante os objetos que circulam no experimento (Latour), seja pelos enquadramentos realizados 
pelos indivíduos por mediação da linguagem (Goffman), os quais podem ser relacionados a diferentes convenções e arranjos locais entre as convenções (Boltanski, Thevenot, Favereau). Nessa perspectiva, os experimentos podem auxiliar a explicitação de convenções e novos enquadramentos, gerados de baixo para cima, não previstos pela teoria.

\section{Artigo recebido em 11.05.2009. Aprovado em 11.08.2010.}

\section{Notas}

\footnotetext{
${ }^{1} \mathrm{O}$ problema com o tit-for-tat é que qualquer erro reverbera em todos os lados. Um lado pune o outro por um desvio e isso inicia uma reação em cadeia.

${ }^{2}$ Pode-se assumir que entre duas partes em uma interação face a face, padrões de mutuo respeito serão estabelecidos - ainda que, às vezes, bem próximos do mínimo. De forma breve, as interações face a face são arenas de conduta, não são meramente expressão e comunicação e a conduta é primeiramente julgada não em face da sinceridade e candor, mas da adequação.
}

\section{Referências}

Abell, P. (2000). Sociological theory and rational choice theory. In B. S. Turner (Ed.), The blackwell companion to social theory (pp. 223-244). Oxford: Blackwell.

Allison, G. T., \& Zelikow, P. (1999). Essence of decision: explaining the Cuban missile crisis. Reading, MA: Longman.

Antiqueira, J. R. M., Saes, M. S. M., \& Lazzarini, S. G. (2007). Comportamento oportunista em negociações envolvendo ativos específicos: um estudo com metodologia experimental. Revista de Gestão USP, 42(4), 393-404.

Axelrod, R. M. (1984). The evolution of cooperation. New York: Basic Books.

Bendor, J., \& Swistak, P. (1997). The evolutionary stability of cooperation. The American Political Science Review, 91(2), 290-307.

Binmore, K. (1994). Playing fair: game theory and the social contract. Cambridge, MA: MIT Press.

Boltanski, L., \& Thévenot, L. (1991). De la justification: les économies de la grandeur. Paris: Gallimard.

Bottom, W. P., Gibson, K., Daniels, S. E., \& Murnigham, J. K. (2002). When talk is no cheap: substantive penance and expressions of intent in rebuilding cooperation. Organization Science, 13(5), 497-513.

Boyd, R., \& Lorberbaum, J. (1987). No pure strategy is evolutionary stable in the repeated prisoner's dilemma game. Nature, 327, 58-59.

Camerer, C. F. (1991). Does strategy research need game theory? Strategic Management Journal, 12(S2), 137-152.

Coleman, J. (1990). Foundations of social theory. Cambridge: Harvard Univ. Press.

Colman, A. M. (2003). Cooperation, psychological game theory, and limitations of rationality in social interaction. Behavioral and Brain Sciences, 26(2), 139-198. 
Coser, L. A. (1956). The functions of social conflict. New York: Free Press.

Coulon, A. (1995). Etnometodologia. Petrópolis, RJ: Vozes.

Davis, D. D., \& Holt, C. A. (1993). Experimental economics. New Jersey: Princeton University Press.

Dawes, R. M. (1980). Social dilemmas. Annual Review of Psychology, 31, 169-193.

Dawes, R. M., \& Messick, D. M. (2000). Social dilemmas. International Journal of Psychology, $35(2), 111-116$.

Dixit, A. K., \& Nalebuff , B. J. (1991). Thinking strategically: the competitive edge in business, politics, and everyday life. New York: W. W. Norton \& Company.

Elster, J. (1983). Sour grapes: studies in the subversion of rationality. New York: Cambridge University Press.

Favereau, O. (1997). L'incomplétude n'est pas le problème, c'est la solution. In J. P. Dupuy \& P. Livet (Eds.), Les limites de la rationalité (pp. 219-234). Paris: Éditions la Découverte.

Favereau, O. (2005). The missing piece in rational choice theory. Revue Française de Sociologie, 46(Suppl.), 103-122.

Fehr, E., \& Fischbacher, U. (2002). Why social preferences matter: the impact of non-selfish motives on competition, cooperation and incentives. The Economic Journal, 112(478), C1-C33.

Frohlich, N., \& Oppenheimer, J. A. (1996). Experiencing impartiality to invok fairness in the N-PD: some experimental results. Public Choice, 86(1/2), 117-135.

Gillespie, J. J., Brett, J. M., \& Weingart, L. R. (2000). Interdependence, social motives, and outcome satisfaction in multiparty negotiation. European Journal of Social Psychology, 30(6), 779-797. doi: 10.1002/1099-0992

Goffman, E. (1959). The presentation of self in everyday life. Garden City, NY: Doubleday Anchor Books.

Goffman, E. (1967). Interaction ritual: essays on face-to-face behavior. New York: Pantheon.

Goffman, E. (1969a). Expression games: an analysis of doubts at play. In E. Goffman (Ed.), Strategic Interaction: an analysis of doubt and calculations in face-to-face, day-to-day dealings with one another (pp. 3-103). New York: Ballantine Books.

Goffman, E. (1969b). Strategic interaction. In E. Goffman (Ed.), Strategic interaction: an analysis of doubt and calculations in face-to-face, day-to-day dealings with one another (pp. 107-182). New York: Ballantine Books.

Goffman, E. (1974). Frame analysis. New York: Harper.

Habermas, J. (2003). Truth and justification (B. Fultner, Trad.). Cambridge, MA: MIT Press. (Obra original publicada em 2003).

Hardin, G. (1968) .The tragedy of the commons. Science, 162(3859), 1243-1248.

Heckathorn, D. (2001). Sociological rational choice. In G. Ritzer \& B. Smart (Eds.), Handbook of Social Theory (pp. 273-284). London: Sage Publications.

Hedstrom, P., \& Swedberg, R. (1996). Rational choice, empirical research, and the sociological tradition. European Sociological Review, 12(2), 127-146. 
Kollock, P. (1998). Social dilemmas: the anatomy of cooperation. Annual Review of Sociology, 24, $183-214$.

Komorita, S. S., Sweeney, J., \& Kravitz, D. A. (1980). Cooperative choices in the N-person dilemma situation. Journal of Personality and Social Psychology, 38(3), 504-516.

Kreps, D. M. (1990). Game theory and economic modeling. Oxford: Clarendon Press.

Latour, B. (1991). Technology is society made durable. In J. Law (Ed.), A sociology of monsters: essays on power, technology and domination (pp. 103-131). New York: Routledge.

Latour, B. (1996). On interobjectivity. Mind, culture, and activity, 3(4), 228-245.

Ledyard, J. O. (1995). Public goods: a survey of experimental research. In J. H. Kagel \& A. E. Roth (Eds.), The handbook of experimental economics (pp. 111-181). New Jersey: Princeton University Press.

Liebrand, W. B. G., Wilke, H. A. M., Vogel, R., \& Wolters, F. J. M. (1986). Value orientation and conformity: a study using three types of social dilemma games. Journal of Conflict Resolution, 30(1), 77-97.

Malhorta, D., \& Murnighan, J. K. (2002). The effects of contracts on interpersonal trust. Administrative Science Quarterly, 47(3), 534-559.

Marsden, P. (1981). Introducing influence processes into a system of collective decisions. American Journal of Sociology, 86(6), 1203-1235.

Marwell, G., \& Ames, R. E. (1980) Experiments on the provision of public goods. I. Resources, interest, group size, and the free-rider problem. The American Journal of Sociology, 84(6), $1335-1360$.

McClintock, C. G., \& Liebrand, W. B. G. (1988). Role of interdependence structure, individual value orientation, and another's strategy in social decision making: a transformational analysis. Journal of Personality and Social Psychology, 55(3), 396-409.

Messick, D. M., \& Brewer, M. B. (1983). Solving social dilemmas. In L. Wheeler \& P. Shaver (Eds.), Review of Personality and Social Psychology (pp. 11-44). Beverly Hills, CA: Sage.

Mintzberg, H., Ahlstrand, B., \& Lampel, J. (2000). Safari de estratégia: um roteiro pela selva do planejamento estratégico (N. Montingelli \& C. A. V. Rossi, Trad.). Porto Alegre: Bookman. (Obra original publicada em 1998).

Möllering, G. (2001). The nature of trust: from Georg Simmel to a theory of expectation, interpretation and suspension. Sociology, 35(2), 403-420.

Neumann, J., von, \& Morgenstern, O. (1944). Theory of games and economic behavior. Princeton, NJ: Princeton University Press.

Offerman, T., Sonnemans, J., \& Schram, A. (1996). Value orientations, expectations, and voluntary contributions in public goods. The Economic Journal, 106(437), 817-845.

Olson, M. (1965). The logic of collective action: public goods and the theory of groups. Cambridge, MA: Harvard University Press.

Ostrom, E. (2000). Collective action and the evolution of social norms. Journal of Economic Perspectives, 14(3), 137-158.

Ostrom, E., Walker, J., \& Gardner, R. (1992). Covenants with and without a sword: self-governance is possible. The American Political Science Review, 86(2), 404-417. 
Parkhe, A. (1993) Strategic alliance structuring: a game theoretic and transaction cost examination of interfirm cooperation. Academy of Management Journal, 36(4), 794-829.

Pillutla, M. M., \& Chen, X. (1999). Social norms and cooperation in social dilemmas: the effects of context and feedback. Organizational Behavior and Human Decision Processes, 78(2), 81-103.

Pillutla, M. M., \& Murnighan, J. K. (1995). Being fair or appearing fair: fairness in ultimatum bargaining. Academy of Management Journal, 38(5), 1408-1426.

Rawls, A. W. (1992). Can rational choice be a foundation for social theory? Theory and Society, 21(2), 219-241.

Sapsed, J., \& Salter, A. (2004). Postcards from the edge: local communities, global programs and boundary objects. Organization Studies, 25(9), 1515-1534.

Sauaia, A. C. A, \& Zerrenner, S. A. (2009). Jogos de empresa e economia experimental: um estudo da racionalidade organizacional na tomada de decisão. Revista de Administração Contemporânea, 13(2), 189-209. doi: 10.1590/S1415-65552009000200003

Schelling, T. C. (1980). The strategy of conflict. Cambridge, MA: Harvard University Press.

Segre, S. (1998). Business communities and their milieux: a reappraisal of Toennies, Weber, and Simmel. International Journal of Politics, Culture, and Society, 11(3), 411-437.

Sen, A. K. (1970). Collective choice and social welfare. San Francisco: Holden-Day.

Simmel, G. (1955). Conflict and the web of group-affiliations (K. H. Wolff, Trad.). Glencoe, IL: The Free Press. (Obra original publicada em 1922).

Stark, D. (2009). The sense of dissonance: accounts of worth in economic life. Princeton, NJ: Princeton University Press.

Swedberg, R. (2000). Max Weber and the idea of economic sociology. Princeton: Princeton University Press.

Swedberg, R. (2001). Sociology and game theory: contemporary and historical perspectives. Theory and Society, 30(3), 301-335.

Swidler, A. (1986). Culture in action: symbols and strategies. American Sociological Review, 51(2), 273-286.

Tenbrunsel, A. E., \& Messick, D. M. (1999). Sanctioning systems, decision frames, and cooperation. Administrative Science Quarterly, 44(4), 684-707.

Thevenot, L. (2002). Conventions of co-ordination and the framing of uncertainty. In E. Fullbrook (Ed.), Intersubjectivity in economics: agents and structures (pp. 181-197). London: Routledge.

Tureta, C., \& Alcadipani, R. (2009). O objeto na análise organizacional: a teoria ator-rede como método de análise da participação dos não-humanos no processo organizativo. Cadernos Ebape.br, VII(1), 50-70.

Vaughan, D. (1998). Rational choice, situated action, and the social control of organizations. Law \& Society Review, 32(1), 23-61.

Weber, M. (2009). Economia e sociedade (G. Cohn, Trad.). Brasília: Universidade de Brasília. (Obra original publicada em 1922). 